\title{
Nigerian Wood Waste: A Potential Resource for Economic Development
}

\author{
*11PETER, AKHATOR; ALBERT, OBANOR; ANTHONY, UGEGE \\ ${ }^{1,2,3}$ Department of Mechanical Engineering, University of Benin, Benin City, Nigeria \\ apeter.akhator@uniben.edu, ${ }^{b}$ aiobanor@yahoo.com, ${ }^{2}$ omoikeugege@yahoo.com \\ Corresponding Author: peter.akhator@uniben.edu
}

\begin{abstract}
Wood waste generation in Nigeria is constantly on the increase as a result of low average percentage timber recovery both in the forests and wood processing industries and increased demand for wood and its products in the country. Being perceived as mere useless materials to be discarded, wood waste has become a menace to public health and the environment in Nigeria due to its indiscriminate disposal practices. This paper therefore aims to highlight the potentials of wood waste as a viable resource for economic growth and sustainable development and thereby pique the people's interest in the proper management and harnessing of wood waste. ( ) JASEM

https://dx.doi.org/10.4314/jasem.v21i2.4
\end{abstract}

Keywords: Sustainable development, Wood waste, Wood waste management, Wood waste utilization.

Nigeria's climate varies from tropical rain forest in the south, to savannah in the middle belt and arid/semi-arid in the north (USAID, 2008). The huge volume of rainfall annually enables forest reserves to thrive throughout the country. Around 11million hectares of forest and about 5.5million hectares of other wooded land are available in Nigeria (FAO, 2005). Round woods in Nigeria are mostly from the southern region; Cross Rivers, Delta, Ogun, Edo, Ekiti, Ondo, Oyo and Osun states, as a result of high annual rainfall in the region [(FAO, 2005). These woods are processed in the various wood processing industries; sawmill industries, plywood mills, furniture industries, pulp and paper industries and particleboard mills (Mijinyawa et al., 2010), in the country. The activities at these forests, wooded lands and wood processing industries generate huge volume of wood wastes that could be harnessed to produce value added products.
Sawmills account for over $93 \%$ of the entire wood processing industries in Nigeria (Ogunwusi, 2014). The activities at these sawmills have led to the generation of huge quantity of wood wastes. Having obtained logs of wood from the forest, the saw millers process them into lumbers of various forms and sizes in their mills. Several wood wastes including sawdust, slabs, bark, split wood, etc. are generated during this process. Although sawmills are the largest sector of wood processing in Nigeria, wood wastes are also generated from other wood processing industries, like the furniture industries, plywood mills and particleboard mills. Wood wastes are also generated from municipal and industrial activities. Table 1 shows the proportion of wood waste from the various sources and the various wood waste types

Table 1: Wood waste proportion and types generated from various sources in Nigeria.

\begin{tabular}{|c|c|c|}
\hline Source & $\begin{array}{l}\text { Average wood waste } \\
\text { generated }(\%)\end{array}$ & Type of wood waste \\
\hline Forest & 50 & $\begin{array}{c}\text { Branches, leaves, needles, stumps, roots, low grade and decayed wood, } \\
\text { slashing and sawdust }\end{array}$ \\
\hline Sawmill & 43 & Bark, sawdust, trimmings, split wood, planer shavings, sander dust. \\
\hline Plywood mill & 45 & $\begin{array}{c}\text { Bark, core, sawdust, lillypads, veneer clippings and waste, panel trim, } \\
\text { sander dust }\end{array}$ \\
\hline Particleboard mill & 5 & Bark, screening fines, panel trim, sawdust, sander dust \\
\hline Furniture industry & 40 & Planer shavings, sawdust, panel trim, sander dust, chips \\
\hline $\begin{array}{l}\text { Municipal \& industrial } \\
\text { activities }\end{array}$ & "NA & $\begin{array}{c}\text { Pruned tree branches, stumps, whole trees, wooden pallets, whole } \\
\text { furniture, furniture pieces }\end{array}$ \\
\hline
\end{tabular}

NA: Not available. Source: (modified from Ogunwusi, 2014) 
Sambo (2009) estimated the amount of sawdust generated per annum in Nigeria to be about 1.8million tonnes, while Francescato et al. (2008) reported a figure for wood residues to be about 5.2million tonnes per year. Due to poor management methods these vast amount of wood residues are often discarded as useless materials, usually untreated, into the environment where they cause adverse effects. Disposal methods such as heaping at industrial sites, dumping on road sides, drainages or water bodies and open air burning are common practices. Some of these industries situated close to banks of rivers often dump their residues into the rivers. These indiscriminate disposal practices result in untoward environmental and human impacts; unsightly look of the environment, air pollution, respiratory tract infection, eye problems, contamination of rivers and ground waters, distortion of water eco-systems and contribution to climate change (Arimoro et al., 2007; Nwankwo, 1998; Wihersaari, 2005). These wastes disposal practices contradict sustainable solid waste management which entails various activities that encourage the efficient utilization of material resources to reduce the amount of waste produced and the management of waste generated in such a way that the economic, social and environmental goals of sustainable development are largely achieved (Pianosi, 2012). According to (IISD, 2016), sustainable development is a development that satisfies the needs of the present generation without jeopardizing the ability of future generations to meet their own needs. Most countries are enacting policies that encourage waste reduction and promote effective waste utilization. The ability of any country to adapt, become more eco-friendly and resource efficient while still competitive depends on its level of ecoinnovation (European Commission, 2014). Globally, it is becoming more and more imperative to reduce resource utilization and its environmental impacts while maintaining a steady rise of competitiveness. Using recycled resources in production processes instead of new materials usually result in less consumption of energy and original materials, less waste landfilled, and less Green House Gas (GHG) emissions over a product's life cycle. Figure 1 shows various wood processing activities including debarking, trimming and planing in a typical Nigerian sawmill.
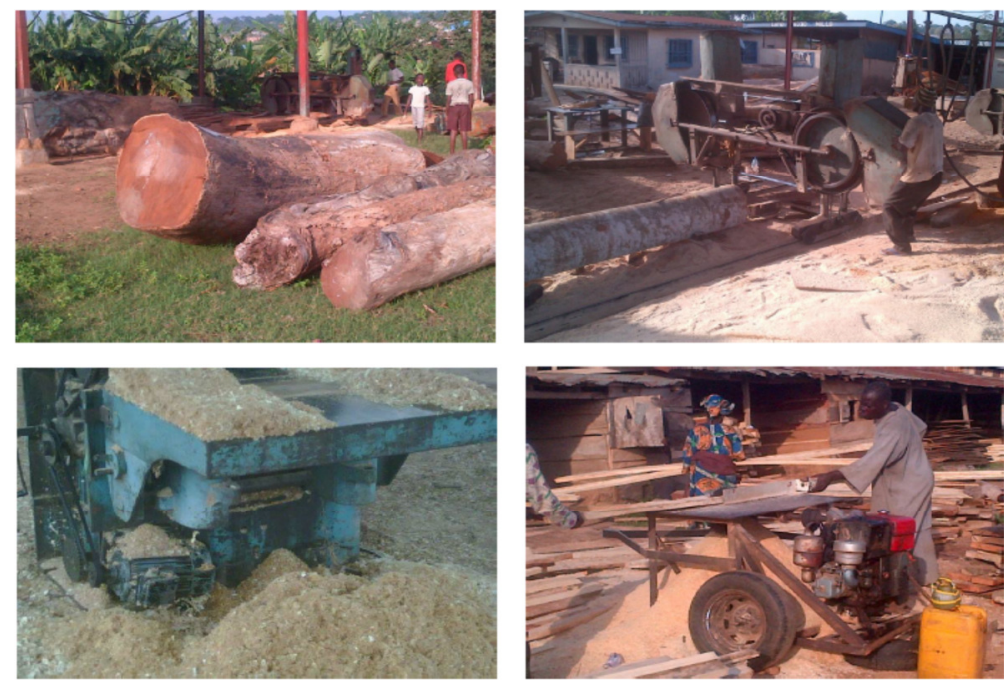

Fig 1: Activities that generate wood waste in a typical Nigerian sawmill (Babayemi et al., 2010) 
Fig 2 shows collection and dumping of wood waste in and around a typical Nigerian sawmill.
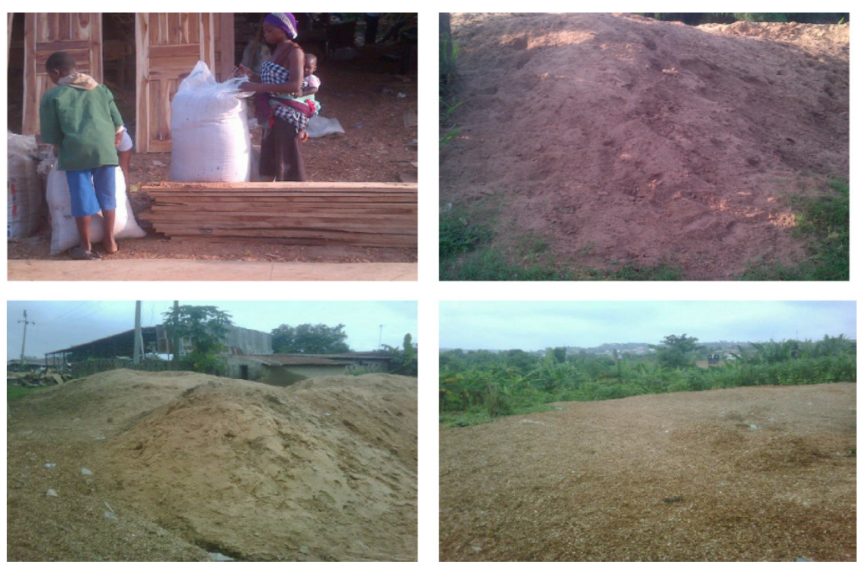

Fig 2: Local collection and dumping of wood waste in and around a Nigerian sawmill (Babayemi et al., 2010)

Quantity of wood waste generated in Nigeria is constantly on the increase. This is adduced to low average percentage of timber recovery both in the forest and wood processing industries, due to the use of obsolete equipment and production processes, coupled with increased demand for wood and its products in the country (Ogunwusi, 2014). To ensure proper and economic management of these wood wastes, they must no longer be regarded as mere useless materials to be discarded but as useful resources of economic value from which energy, fuel and other by-products can be harnessed. This paper aims to highlight the potentials of wood waste as a viable resource for economic growth and sustainable development with the view to pique the people's interest in the proper management and harnessing of wood waste.

\section{MATERIALS AND METHODS}

The study originated from the need to present wood wastes as viable resources of economic value from which energy, fuel and useful by-products, capable of stimulating sustainable development, can be harnessed. The study involved field visits to several saw mills in Benin City, Edo State, Nigeria to physically observe wood processing activities, volume of wood wastes generated and methods of wood wastes disposal. Structured questionnaires were administered to workers at the various sawmills in order to acquire necessary information that will enhance the output of the study. The questionnaires were designed to determine the current uses and potential utilization of wood wastes generated among others. In addition, a desk research was also carried out to ascertain the factors limiting the utilization of wood wastes in Nigeria as well as sustainable utilization of wood wastes in other climes.

\section{RESULTS AND DISCUSSION}

Factors Limiting the Utilization of Wood Wastes in Nigeria: Locally, wood wastes currently enjoy patronage in areas like beddings for animals, cooking, cleaning of tiles and materials for the production of flower vases, bowls, etc. In addition, wood wastes are also used by farmers as farm manure and to protect yam seedlings from excessive water and sun rays. These uses for wood wastes account for a little percentage of wood wastes generated in Benin Metropolis as evident from the huge quantity of wood wastes littering the premises of sawmills and other wood processing industries in the metropolis. Ogunwusi (2014) reported less than 5\% utilization of the total wood waste generated in Nigeria. This leaves huge quantity of wood waste unutilized. The poor utilization of wood waste in Nigeria can be adduced to several factors; lack of incentives for wood waste utilization, inadequate information on economic returns of wood waste utilization, poor enforcement of environmental regulations, absence of policies targeted at wood waste management, lack of technical know-how on wood waste processing and utilization, among others.

Sustainable Utilization of Wood Wastes: The current utilization rate of wood and low recovery efficiency of wood in the forests and wood industries poses a 
grave threat to sustainability especially in the wood industries. Hence the need to find sustainable uses for wood wastes. This would reduce the cutting and processing of trees as well as make more trees available to act as carbon sink. Sustainable wood waste utilization would drastically reduce volume of wood waste, ensure total tree utilization, reduce production costs and enhances environmental cleanliness. It will also prevent open burning of wastes thus mitigating climate change. Several value added products have been harnessed from wood wastes. These products have eliminated most of the negative implications posed by indiscriminate disposal and poor management of wood wastes. Some of the economic management and potential utilization of wood waste that can turn its perception as mere waste to useful resource in Nigeria are subsequently discussed.
A. Energy Generation: Biomass is a renewable energy resource which can be used to produce

B. electricity, heat and transportation fuels. Although biomass can come from many different sources, wood is by far the most common (Bourguignon, 2015). The use of woody biomass for energy generation can offset fuels such as coal, gasoline, natural gas, oil, etc. Such practice can enhance economic development and foster new industries making bio-based products. According to Bourguignon (2015), about $46 \%$ of renewable energy consumed in the European Union (EU) came from solid biomass (almost exclusively wood) in 2015 and, in 2013, solid biomass accounted for $3 \%$ of the electricity produced in the EU and $15 \%$ of the heat produced in industrial sectors. Figure 3 shows solid biomass contribution to renewable energy in EU28 in million tonnes of oil equivalent (Mtoe) from 2004 to 2013.

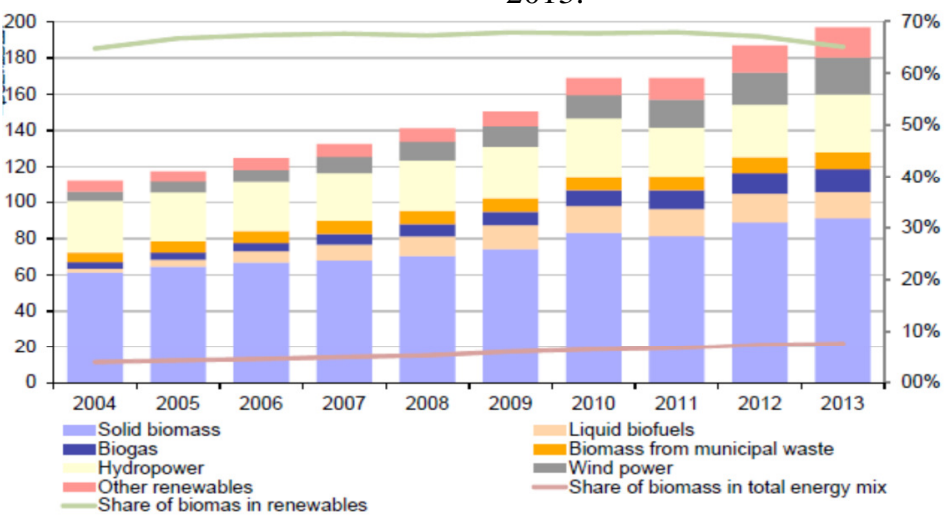

Fig 3: Renewable energy sources in EU28 in Mtoe from 2004 to 2013 (Bourguignon, 2015).

Also in 2013, the European solid biomass and biogas sectors generated a turnover of about 42billion Euro and employed over 300 thousand people (Bourguignon, 2015).

Wood can contribute to the energy mix in Nigeria. Uzoma et al. (2012) reported that no single energy resource can sustainably satisfy the energy demands of any country. Although, Nigeria's energy mix at present comprises natural gas and hydro, the electricity generated is still grossly inadequate to meet the national demand. Utilizing the enormous amount of wood waste in Nigeria for energy generation would greatly complement the electricity available from the national grid, reduce blackouts and brownouts, boost economic activities and assist in the effort to properly manage it. Such wood waste utilization would also contribute to achieving the goals of Nigeria's Renewable Energy Master Plan (REMP), which is to have biomass-based power plants with installed capacity of 50MW in 2015 and 400MW in 2025 (IEA, 2011).
Many biomass-to-energy technologies are advanced with affordable production costs particularly where low cost agricultural or forestry waste are available (IRENA, 2012). These technologies include combustion, gasification and pyrolysis. Combustion technology involves recovering energy from wood waste through the production of steam in boiler super-heater tubes. The steam may be used to generate electricity in a steam turbine generator or sold directly for commercial or process heat purposes. Gasification converts wood waste into synthethic gas which can be utilized to produce steam in boiler super-heater tubes, to generate electricity directly in an internal combustion (IC) engine or as transportation fuels. Pyrolysis converts wood waste into bio-oil and bio-char from which energy can be obtained.

C. Engineered Wood Products: This is another important utilization option for wood wastes. Engineered woods are woody products obtained by binding smaller pieces of wood together using glues, 
resins, etc. (Tariq, 2013). Examples of engineered wood products are medium density fibreboard (MDF), oriented strand-board, particleboard, wood Ijoists, etc., with MDF being the most important. Medium-density fibreboard (MDF) is a non-structural panel made from fibres produced from wood chips through a mechanical refining process. It is generally used for industrial purposes as a raw material in the production of finished goods, including ready-toassemble furniture and cabinets. MDF is composed of wood fibres bonded together with special resins at high temperature and pressure. The fibres are produced using a pulping process in which wood chips are treated with steam and broken down into fibres in a defibrator. Mats are then formed by allowing the fibres distribute themselves randomly, resulting in a very homogeneous panel.

D.

MDF has a wide range of uses; in factory-assembled and ready-to-assemble furniture, kitchen cabinets and doors, bases for kitchen counters, book cases, moulding, shelving and furniture etc. Globally, the use of MDF has grown substantially in recent decades. Over $40 \%$ of the world's MDF is now produced in China, feeding the country's rapidly growing furniture industry. In 2012, Canada produced 440,000 cubic metres of MDF while the U.S. produced 1.6 million cubic metres (Natural Resources Canada, 2016).

E. Production of Chemicals and Medicines: Chemicals and medicines can be obtained from wood waste, especially bark. Bark is the outer covering of trees. It has useful by-products waiting for the right economic conditions for the development of satisfactory commercial purposes. Efficient bark utilization can create a new industry and boost the economy by turning a costly waste into valuable asset. A most interesting utilization of bark is as a source of chemical extracts with medicinal or physiological properties. These extracts can be harnessed to produce important products like tannins, adhesives, quinine, flavouring, aphrodisiac (used by animal breeders), antibiotics, latex materials, dyes, etc. Cork, fibre and charcoal are other by-products obtainable from wood bark (Tariq, 2013).

F. Production of Insulation Materials: Wood is a good thermal insulator and therefore wood wastes can also be used to produce wood-based insulation materials. Industrially produced wood-based insulation materials was introduced several years ago after engineers from the timber producing areas of Europe devised new ways of transforming timber waste from thinnings and factories into insulation boarding. The success of wood fibre insulation (with thermal conductivity values between 0.038-0.043 $\mathrm{W} / \mathrm{mK}$ ) derives from an attractive environmental profile combined with several functions including rigid insulation, sheathing and sarking for timber frames, roofs and flooring as well as flexible insulation for studs and rafters. Other features include 'breathability' that helps to regulate moisture as well as a material density suffice, that helps to delay decrement, useful during hot days (GreenSpec, 2016). Use of wood-based material for insulation will lower energy consumption at the production stage, reduce the products' carbon footprint, involve no health hazards and enhance sustainability of forests and wood industries.

G. Export: Export could be a long term and profitable management method for wood wastes. According to (Bourguignon, 2015), about 18million tonnes of wood pellets were consumed in the EU in 2013. A third is currently being imported mainly from the USA, Russia, Ukraine and Belarus. Based on national estimates, the European Commission anticipates an increase in biomass supply for electricity and heating from 103.3 Mtoe in 2012 to about 132 Mtoe in 2020 (Bourguignon, 2015). The European Commission also expects imports from third countries to increase by 2020 , largely in the form of wood chips and wood pellets. Globally, wood pellets consumption is projected to rise from 22 to about 80 million tonnes by 2020 (Bourguignon, 2015). This could be a lucrative market for Nigeria wood wastes when properly managed.

Conclusion: The potentials of wood wastes were highlighted in this paper. It was revealed that wood wastes enjoy utilization for the production of various value added products. Such utilization of wood wastes would assist to achieve the goals of sustainable development, mitigate climate change, develop bio-based businesses, create wealth, enhance the efficiencies of forests and wood processing industries, improve wood waste management and stimulate domestic economic development. However, appropriate policies and incentives need to be in place to encourage waste utilization and prevent the menace from its indiscriminate disposal.

\section{REFERENCES}

Arimoro, FO; Ikomi, RB; Osalor, EC (2007). The impact of sawmills wood wastes on the water quality and fish communities of Benin River, Niger delta area, Nigeria. International Journal of Science and Technology, 2(1): 1-12.

Babayemi, JO; Dauda, K.T (2010). Evaluation of Solid Waste Generation, Categories and Disposal 
Options in Developing Countries: A Case Study of Nigeria. Journal of Applied Sciences and Environmental Management, 13: 83-88.

Bourguignon, D (2015). Biomass for electricity and heating: opportunities and challenges. A report presented to the European Parliamentary Research Service. Available at http://www.europarl.europa.eu/ RegData/etudes/ BRIE/2015/ 568329/ EPRS BRI(2015)568329EN.pdf. (Accessed on May/20/2016).

European Commission (EC) (2014). Climate Action, Environment, Resource Efficiency and Raw Materials. Horizon 2020. The EU framework programme for research and innovation, unpublished.

Food and Agriculture Organization (FAO) of the United Nations (2005). Global Forest Resources Assessment. Available at http://www.fao.org/docrep/008/a0400e/a0400e00 .HTM. (Accessed on June/12/ 2016).

Francescato, V; Antonini, E; Bergomi, L.Z; Metschina, C; Schnedl, C; Krajnc, N; Koscik, K; Gradziuk, P; Nocentini, G; Stranieri, S (2008). Wood Fuels Handbook. AIEL: Italian Agriforestry Energy Association, Legnaro.

GreenSpec (2016). Wood fibre insulation: introduction. Available at http://www.greenspec.co.uk/buildingdesign/woodfibre-insulation-intro/. (Accessed on July/12/2016).

International energy Agency (IEA) (2011). Nigeria Renewable Energy Master Plan. Available atwww.iea.org/policiesandmeasures/pams/nigeri a/name-24808-en.php? (Assessed on February/5/2015).

IISD (2016). Sustainable development. Available at http://www.iisd.org/topic/sustainabledevelopment. (Accessed on July/12/1026).

IRENA (2012). Renewable power generation costs. Available at

http://www.irena.org/DocumentDownloads/Publicati ons/Renewable_Power_Generation_Costs.pdf. (Accessed on June/20/2016).

Mijinyawa, Y; Bello, SR (2010) Assessment of Injuries in Small Scale Sawmill Industry of
South Western Nigeria. Agricultural Engineering International: The CIGR Journal of Scientific Research and Development, 12: 157-157.

Natural Resources Canada (2016). Medium density fibreboard. Available at http://www.nrcan.gc.ca/forests/industry/products -applications/15849. (Accessed on July 12/2016).

Nwankwo, DI (1998). The influence of sawmill wood waste on diatom population at Okobaba. Lagos, Nigeria. Nigerian Journal of Botany. 11: 15-24.

Ogunwusi, AA (2014). Wood Waste Generation in the Forest Industry in Nigeria and Prospects for Its Industrial Utilization. Civil and Environmental Research, 6(9): 2224-5790.

Pianosi, M. (2012). Sustainable waste management. Available at

https://torinobyveg.wordpress.com/2012/11/19/s ustainablewastesustainablewastemanagement/ (Accessed on July/06/2016)

Sambo, AS (2009). The Place of Renewable Energy in the Nigerian Energy Sector. World Future Council

Workshop on Renewable Energy Policies, 10 October 2009, Addis Ababa, Ethiopia.

Tariq, Z (2013). Utilization of wood waste, logging and industrial waste, Arid Agriculture University. Available at www.academia.edu/3072505/Utilization_of_woo d_waste (Accessed October12, 2016).

United States Agency for International Development (USAID) (2008). Nigeria biodiversity and tropical forestry assessment. Available at http://pdf.usaid.gov/pdf_docs/Pnadn536.pdf (Accessed February 1/2017).

Uzoma, CC; Nnaji, CE; Nnaji, M (2012). The Role of Energy Mix in Sustainable Development of

Nigeria. Continental J. Social Sciences, 5 (1): $21-29$.

Wihersaari, M. (2005). Evaluation of Greenhouse Gas Emissions Risk from Storage of Wood Residues. Biomass and Energy, 28: 444-453. 